\title{
Percepção dos tutores sobre alimentação oferecida para animais de companhia no brejo paraibano ${ }^{1}$
}

\author{
Rosana do Nascimento Ribeiro ${ }^{2}$, Débora Cristina Basílico Crispim da Silva², Lucas Rannier Ribeiro \\ Antonino Carvalho ${ }^{2}$, Helder Camilo da Silva Pereira ${ }^{2}$, Tarsys Noan Silva Veríssimo ${ }^{2}$, Ricardo Romão \\ Guerra $^{2}$
}

Resumo: O trabalho teve como objetivo principal descrever o perfil dos tutores oriundos do brejo paraibano no que diz respeito à alimentação de seus animais de companhia (cães e gatos). Foram aplicados a tutores do brejo paraibano, nas cidades de Alagoa Grande, Areia, Pilões, Guarabira e Serraria, 500 questionários semiestruturados, subdivididos em 100 questionários por cidade. O questionário trazia a identificação do animal e questões sobre alimentação animal. A aplicação foi ao acaso, abordando pessoas que transitavam nas zonas urbanas das cidades, que tinham animais domiciliados e que concordavam em colaborar com a pesquisa. Houve diferença significativa no número de cães e gatos alimentados com ração industrializada, onde cães comiam mais ração industrializada $(\mathrm{p}=0,023)$. A frequência com que os gatos $(\mathrm{p} \leq 0,001)$ são alimentados se mostrou maior que os cães. Tutores de cães mostraram-se mais propensos a adquirir alimento com preço mais baixo $(p=0,018)$, também mostraram um maior conhecimento quanto à relação da alimentação e a saúde dos animais $(\mathrm{p}=0,009)$ e à possibilidade de tratamento e cura de doenças por meio da alimentação $(p=0,028)$. Os tutores de cães aparentam estar melhores informados quanto à qualidade e características dos alimentos para seus animais, porém, na prática, tutores de ambas as espécies não possuíam níveis econômicos suficiente para investirem em alimentos de melhor qualidade.

Palavras-Chave: Cães; Gatos; Qualidade; Questionários; Ração industrializada.

\section{Tutors' perception of the food offered to pets in the brejo paraibano}

\begin{abstract}
The main objective of this work was to describe the profile of tutors from Brejo Paraibano with regard to the feeding of their companion animals (dogs and cats). 500 semi-structured questionnaires, subdivided into 100 questionnaires per city, were applied to tutors from the Paraíba swamp in the cities of Alagoa Grande, Areia, Pilões, Guarabira and Serraria. The questionnaire included the identification of the animal and questions about animal feed. The application was randomized, addressing people who moved in urban areas of the cities and who had domesticated animals and who agreed to collaborate with the research. There was a significant difference in the number of dogs and cats fed industrialized food, where dogs ate more industrialized food $(p=0,023)$. The frequency with which cats $(\mathrm{p} \leq 0,001)$ are fed proved to be higher than dogs. Dog tutors were more likely to purchase food at a lower price $(\mathrm{p}=0,018)$, they also showed greater knowledge about the relationship between food and animal health $(\mathrm{p}=0,009)$ and the possibility of treating and curing diseases through feeding $(\mathrm{p}=0,028)$. Dog guardians seem to be better informed about the quality and characteristics of food for their animals, however, in practice, guardians of both species did not have sufficient economic levels to invest in better quality food.
\end{abstract}

Keywords: Dogs; Cats; Quality; Questionnaire; Industrialized animal food.

\footnotetext{
${ }^{1}$ Submetido em 22/01/2020 e aprovado em 07/02/2020;

${ }^{2}$ Universidade Federal da Paraíba, Centro de Ciências Agrárias, Areia, PB, Brasil. E-mail: rosananr.vet@ gmail.com (Autor correspondente) ORCID: https://orcid.org/0000-0001-6541-1634; debrucita@hotmail.com - ORCID: https://orcid.org/0000-0001-6756-7341; lucasrveter@gmail.com - ORCID: https://orcid.org/0000-0002-5875-8573; psicologohelder@ hotmail.com - ORCID: https://orcid.org/00000001-9265-8966; verissimotns@ hotmail.com - ORCID: https://orcid.org/0000-0001-9258-811X; rromaoguerra@gmail.com - ORCID: https://orcid.org/0000-0001-8226-8606
}

Agropecuária Técnica, Areia-PB, v. 41, n. 1-2, p. 25-35, 2020

https://doi.org/10.25066/agrotec.v41i1-2.50373 


\section{Introdução}

Desde os primeiros registros da humanidade o homem realiza interação com os animais, o que resulta em uma relação benéfica para ambas as espécies. A população de cães e gatos tem crescido no decorrer do tempo e sua guarda responsável é fundamental para que se garanta as condições de saúde animal (Garcia, 2009).

Segundo a Pesquisa Nacional de Saúde, realizada pelo Instituto Brasileiro de Geografia e Estatística (IBGE) em 2013, estimou que 44,3\% dos domicílios do país possuíam pelo menos cachorro, o que equivale a 28,9 milhões de unidades domiciliares. A população de cachorros em domicílios brasileiros foi estimada em 52,2 milhões, o que indica uma média de 1,8 cachorro por domicílio. Em relação a presença de gato, 17,7\% dos domicílios do país possuíam pelo menos um, o que equivalente a 11,5 milhões de unidades domiciliadas. A população de gatos em domicílios brasileiros foi estimada em 22,1 milhões, o que representa aproximadamente 1,9 gato por domicílio.

A alimentação desses animais passou por uma evolução nítida nas últimas décadas. Nos anos 80 a maioria dos animais de companhia eram alimentados somente com os restos da comida de seus tutores, e existiam poucas industrias de rações que investiam no Brasil. Dois fatores no passar do tempo contribuíram para o avanço desse mercado, o poder aquisitivo das populações dos grandes centros aumentou e seus padrões de consumo se sofisticaram (Borges et al., 2015).

A Associação Mundial de Medicina Veterinária de Pequenos Animais (WSAVA, 2019) afirma que a nutrição de cães e gatos necessita da mesma atenção que é aplicada a outras espécies a exemplo da humana. Os animais de companhia frequentemente recebem somente uma fonte de alimento seja ela um alimento industrializado ou feito de forma caseira. Porém, é fundamental ser realizado uma avaliação atenciosa de suas necessidades nutricionais afim de manter a saúde e desempenho do animal.

A WSAVA (2019) desenvolveu uma ação global para incluir 5 parâmetros vitais no exame clínico padrão de pequenos animais, na ordem temos: temperatura, pulso, respiração, avaliação da dor e avaliação nutricional. Incluindo a avaliação nutricional como um dos parâmetros vitais a serem sempre avaliados em qualquer exame clínico, incorporando os cuidados nutricionais regulares aos animais como parte a manutenção da saúde deles.

O desenvolvimento equilibrado destes animais é justificado por vários fatores, porém o fator que mais condiciona o animal a uma vida saudável é a nutrição. Adequar o manejo alimentar de cães e gatos pode colaborar com um pleno conceito de saúde e bem estar (Ogoshi et al., 2015).

Nesse intuito, esta pesquisa foi desenvolvida como objetivo principal de caracterizar os tutores da região do brejo paraibano no que diz respeito a alimentação de seus animais de companhia, conhecer qual o principal alimento fornecido a esses animais e tentar compreender se os tutores entendem a relação da alimentação com a saúde de seus animais.

\section{Material e métodos}

Foram aplicados a tutores de cães e gatos da região do brejo Paraibano, nas cidades de Alagoa Grande, Areia, Pilões, Guarabira e Serraria, 500 questionários semiestruturados no total, sendo subdivididos em 100 questionários por cidade. $\mathrm{O}$ questionário teve início com a identificação do animal e em sequência questões sobre nutrição animal. A aplicação se deu de forma aleatória, abordando pessoas que transitavam na zona urbana dessas cidades e que aceitaram colaborar com a pesquisa.

O questionário abordou primeiro a identificação do animal, com os seguintes dados: espécie, sexo e idade do animal; frequência de vacinação, presença de doença crônica e características do local onde o animal era mantido. Foi obtida adicionalmente a renda familiar.

Em relação a temática de nutrição, foi abordado primeiro qual tipo de alimento o tutor oferecia a seu animal e com que frequência o fazia. Em se tratando de o alimento ser ração industrializada, foi registrado de qual marca se tratava. Também foram questionados se no momento da escolha do alimento eles buscavam alguma característica específica, e se fatores como preço ou marca do alimento era um fator determinante na escolha. Foi abordado se os tutores conhecem ou já ouviram falar a respeito 
de ração comercial terapêutica e se sabem diferenciar ração industrializada econômica/premium/premium superior e super premium. Também se eles acreditam haver diferença entre uma mesma ração que é vendida no granel ou em embalagem fechada no que diz respeito a sua qualidade nutricional e segurança alimentar. Os tutores também foram questionados sobre a alimentação natural formulada para animal, se conheciam e se tinham disponibilidade ou não em preparar esse tipo de alimento; quanto a saúde do animal, foram questionados se acreditavam que a alimentação é um fator que interfere de forma positiva e/ou negativa na vida do animal, e se o alimento em determinadas condições pode agir como um recurso de cura ou tratamento para o animal. O questionário encerra perguntando se os tutores já haviam ouvido falar ou se conheciam um nutricionista animal, se levaria seu animal a um, por qual razão o faria, e com que frequência costumam levar seus animais ao médico veterinário.

Ao fim das coletas, os dados foram tabulados e processados utilizando o programa estatístico SPSS versão 25.0. Foi realizada a análise descritiva e teste qui-quadrado de Pearson. Os valores de $\mathrm{p}<0,05$ foram considerados significativos, e os dados expressos em tabelas com frequência relativa e absoluta, além de gráficos circulares.

\section{Resultados e Discussão}

Dos 500 tutores entrevistados $67,4 \%$ (337) eram tutores de cães e 32,6\% (163) eram tutores de gatos. Quanto à renda da população entrevistada, $84,8 \%$ (424) informou receber entre um e três salários mínimos, $13 \%$ (65) recebiam entre três e seis salários mínimos, 1,2\% (6) recebiam entre seis e nove salários mínimos e $1 \%$ (5) recebiam entre nove e 12 salários mínimos, não havendo diferença significativa entre a renda de tutores de cães e tutores de gatos. Na Tabela 1 estão discriminados os dados da renda dos tutores para cada cidade estudada.

Na cidade de Alagoa Grande $87 \%$ de tutores entrevistados recebiam entre um e três salários mínimos, $11 \%$ de três a seis salários e $2 \%$ recebiam de seis a nove salários mínimos mensais. Em Areia, 83\% dos tutores recebiam entre um e três salários mínimos, $15 \%$ entre três e seis salários e $2 \%$ de seis a nove salários mínimos mensais. Oitenta e quatro por cento de tutores da cidade de Pilões recebia entre um e três salários mínimos, $13 \%$ recebia entre três e seis salários e $2 \%$ recebia entre seis e nove salários mínimos. Em Guarabira 82\% dos tutores recebiam entre um e três salários mínimos, $14 \%$ recebiam entre três e seis salários e $2 \%$ recebiam entre seis e nove salários. Por fim, na cidade de Serraria $88 \%$ recebiam entre um e três salários, $12 \%$ recebiam entre três e seis salários e nenhum dos entrevistados nesta cidade afirmou receber entre seis e nove salários mínimos.

Tabela 1 Renda familiar dos tutores de cães e gatos do brejo paraibano

\begin{tabular}{lcccc}
\hline \multicolumn{1}{c}{ Cidade } & $\begin{array}{c}1 \text { a } 3 \\
\text { salários }\end{array}$ & $\begin{array}{c}3 \text { a } 6 \\
\text { salários }\end{array}$ & $\begin{array}{c}6 \text { a } 9 \\
\text { salários }\end{array}$ & Total \\
Alagoa & $---------------~ \%$ & $----------------~$ \\
Grande & 87 & 11 & 2 & 100 \\
Areia & 83 & 15 & 2 & 100 \\
Pilões & 84 & 13 & 2 & 100 \\
Guarabira & 82 & 14 & 2 & 100 \\
Serraria & 88 & 12 & 0 & 100 \\
\hline
\end{tabular}

Um estudo realizado na cidade de Areia, em forma de questionário, foi apresentado aos tutores durante a campanha de vacinação antirrábica e correlacionou o padrão socioeconômico (renda familiar + nível de escolaridade) da população ao nível de informação e cuidados quanto ao manejo com os animais. Dentre os parâmetros avaliados estavam: o tipo de alimentação, o tipo de vacinação necessária para a espécie, a importância da castração e a realização de consultas veterinárias de rotina, e foi demonstrado que quanto maior o nível socioeconômico do tutor, maior a preocupação com o bem estar animal e a guarda responsável dos seus animais (Gomes, 2015).

Em resposta à primeira pergunta do questionário, relacionada ao tipo de alimentação oferecida aos animais, $57,2 \%$ (286) dos tutores afirmou oferecer ração comercial, correspondendo a $61,9 \%$ (177) dos cães e $38,1 \%$ (109) dos gatos, havendo, portanto uma diferença significativa entre as espécies $(p=0,023)$, sugerindo que os tutores de gatos preferem alimentar os seus animais com ração comercial. Quarenta vírgula dois por cento (201) dos tutores respondeu que oferecia sobras de comida caseira para seus animais, onde 74,6\% (150) eram cães e $25,4 \%$ (51) eram gatos. Apenas quatro tutores $(0,8 \%)$ afirmaram oferecer ração terapêutica, sendo dois $(50,0 \%)$ cães e dois $(50,0 \%)$ gatos. E, 
por fim, nove tutores $(1,8 \%)$ afirmaram oferecer ração natural formulada para os seus animais, onde oito $(88,9 \%)$ destes eram cães e um $(11,1 \%)$ gato.

Estudos realizados em outros países, como Estados Unidos e Austrália, já observaram que a maioria dos tutores de gatos prefere alimentar os seus animais com ração comercial, quando comparados aos tutores de cães, que ainda prefere alimentar os seus animais com sobras da alimentação humana, mesmo tendo sido observado um significativo aumento do consumo de ração seca para ambas as espécies por todo o mundo (Aptekmann et al., 2013).

O uso de sobras da alimentação humana para a alimentação animal, tanto para cães quanto para gatos é comum, inclusive alguns tutores afirmam misturar a comida caseira à ração comercial, para torná-la mais atrativa (palatável) para o animal, ou preparar a sua própria alimentação natural, sem seguir nenhuma prescrição quanto à quantidade e qualidade dos ingredientes. Além de fatores como desbalanceamento da refeição do animal, esse hábito pode causar danos ao animal, como intoxicação alimentar causada pela cebola e alho usados no preparo da comida humana ou problemas cardiovasculares causados pelo excesso de sódio, e devem ser corrigidas por um profissional da área que seja habilitado para fazer tal prescrição (Aptekmann et al., 2013; Pedrinelli et al., 2017).

Com relação à frequência de alimentação, as respostas dos tutores estão demonstradas na Figura 1. Os tutores escolheram a opção de alimentar os seus animais três vezes ao dia com maior frequência que as demais formas, correspondendo a 28,8\% (144) dos entrevistados, seguida da frequência de duas vezes ao dia com $27,4 \%$ (137) das respostas. Na pesquisa, $22,8 \%$ (114) afirmaram oferecer alimentos à vontade, $13,0 \%$ ofereciam alimento apenas uma vez ao dia e $8,0 \%$ ofereciam alimentos mais de três vezes ao dia aos seus animais. Foi observada diferença significativa da frequência alimentar entre as duas espécies $(\mathrm{p} \leq 0,001)$, onde os tutores de gatos alimentam os seus animais com maior frequência do que os tutores de cães.

Esse resultado vai de acordo com o observado pelos estudos que avaliaram o perfil de frequência alimentar diária dos tutores dos Estados Unidos, Austrália e Espírito Santo, no Brasil, onde os tutores de cães também preferiram alimentar os seus cães duas vezes ao dia, porém nesses estudos os tutores de gatos afirmaram alimentar os seus animais à vontade, nesses locais (Aptekmann et al., 2013).

\section{Frequência de alimentação}

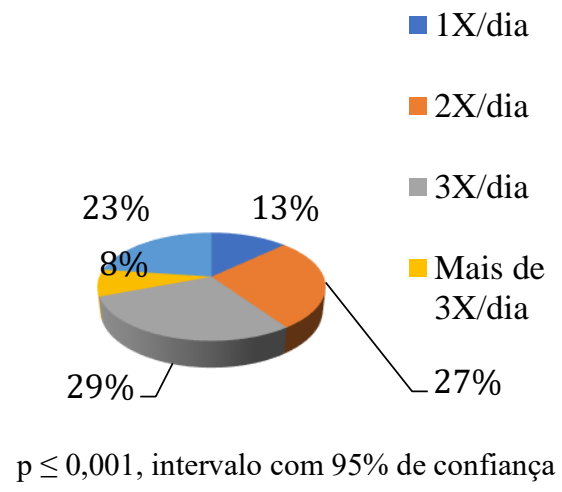

Figura 1 Frequência diária de alimentação dos cães e gatos do brejo paraibano.

Várias pesquisas vêm sendo realizados para se compreender a relação entre a frequência alimentar dos animais e a sua saúde. Esses estudos avaliam vários parâmetros como níveis séricos de colesterol, glicose, ureia, características fecais, termogênese, condição corporal, entre outros, em grupos de animais alimentados com frequências diárias diferentes, porém nenhum desses estudos avaliou a relação da frequência alimentar dos cães diretamente com o estado nutricional. (Deng et al., 2014; Brambillasca et al., 2010).

Dessa forma começa-se a entender a relação do metabolismo animal com a frequência alimentar, os diferentes tipos de alimento e, principalmente, as diferenças entre as espécies. Os gatos têm necessidade de serem alimentados mais vezes ao dia para que consigam manter a sua glicemia e atividade metabólica constantes (Deng et al., 2014).

Vinte e três por cento do total dos entrevistados afirmaram deixar o alimento em livre demanda, o que pode acarretar em problemas como desperdício de alimento, sobrepeso do animal, contaminação acidental do alimento por produtos químicos ou por vetores, risco de alteração do alimento, podendo ocasionar distúrbios gastrointestinais (Borges, 2009; WSAVA, 2019). 
Na Tabela 2 estão as respostas à pergunta que indagava quanto às características buscadas pelos tutores no momento de escolher o alimento dos seus animais.

Tabela 2 Principais características físicas da ração comercial observadas pelos tutores de cães e gatos da região do brejo paraibano (Alagoa Grande, Areia, Pilões, Guarabira e Serraria) no momento da compra

\begin{tabular}{lcc}
\hline Característica & $\begin{array}{c}\mathrm{N} \\
\text { (Cães/Gatos) }\end{array}$ & $\%$ \\
\hline Nenhuma & $196(130 / 66)$ & 39,2 \\
Qualidade & $122(89 / 33)$ & 24,4 \\
O que o animal gosta & $55(37 / 18)$ & 11 \\
Valor nutricional & $44(27 / 17)$ & 8,8 \\
Preço & $29(22 / 7)$ & 5,8 \\
Sabor da ração & $18(11 / 7)$ & 3,6 \\
Não soube dizer & $18(10 / 8)$ & 3,6 \\
Recomendação do & $9(4 / 5)$ & 1,8 \\
veterinário & 5 & 1 \\
Sem corante & $4(2 / 2)$ & 0,8 \\
Marca & \multicolumn{2}{c}{}
\end{tabular}

Exatamente 21,2\% (106) dos tutores ainda são influenciados por características como preço, marca ou aceitação por parte do animal (sabor da ração ou gosto do animal) que podem não estar relacionados diretamente à qualidade daquele alimento. Em contrapartida 36,0\% (180) dos tutores observaram características como valor nutricional, qualidade, recomendação do veterinário e ausência de corantes como determinantes no momento da escolha. Trinta e nove vírgula dois por cento (196) dos entrevistados alegaram não escolher a alimentação dos seus animais por nenhuma característica específica, sugerindo que boa parte dos tutores não considera importante avaliar as características do alimento dos seus animais no momento da compra.

Do total de tutores de cães (337), apenas $37,1 \%$ (125) avaliam características que podem determinar a qualidade do alimento, tutores de gatos (163) somaram apenas 32,5\% (53). Esses dados sugerem que existe certo interesse de parte dos tutores na qualidade da alimentação oferecida aos seus animais, e o entendimento do alimento como parte importante da manutenção da saúde dos seus animais, apesar da maioria ainda não se interessar. Vem sendo observado entre os tutores de diversos países um aumento da preocupação pela qualidade dos alimentos para os animais, principalmente após episódios de intoxicação alimentar de animais pelo consumo de ração contaminada com agentes pesticidas usados na agricultura (Saad; França, 2010; Zicker, 2008).

As rações que são formuladas com ingredientes de menor qualidade tendem a utilizar aditivos para torná-la mais atrativa ao animal, mantendo o nível nutricional e preço comercial baixo em relação às rações comerciais que usam ingredientes de melhor qualidade (Beça, 2013). Tal resultado pode também ser relacionado ao nível socioeconômico dos entrevistados que, como demonstrado, afeta diretamente o discernimento quanto ao bem estar animal (Gomes, 2015).

Para prescrever-se uma dieta apropriada devese avaliar cada caso isoladamente, levando em conta fatores como idade do animal, peso, nível de atividade física, disponibilidade dos tutores, preço final, entre outros. Devem-se conscientizar os tutores quanto à importância de uma alimentação espécie específica balanceada e de qualidade, visto que as necessidades nutricionais dos caninos e felinos são bastante diferentes.

Essa conscientização dos tutores deve ser feita por parte do médico veterinário responsável pelo acompanhamento do animal, que deve buscar se atualizar quanto às melhores alternativas para alimentação dos seus pacientes. A avaliação nutricional do animal deve ser realizada logo no momento da abordagem do paciente, como parte integrada do exame físico geral, juntamente com outros parâmetros como frequência respiratória e cardíaca, temperatura corporal, pulso e avaliação da dor. A medicina preventiva (que inclui a nutrição) deve ser uma constante na rotina do animal, e não apenas a prática da medicina curativa (Borges, 2009; Ogoshi et al., 2015; Remillard, 2008; WSAVA, 2019).

Em resposta à pergunta sobre o conhecimento dos tutores quanto aos diferentes segmentos de rações comerciais existentes, $84,6 \%$ (423) dos tutores alegaram não conhecer a divisão da ração em econômica/premium/premium superior ou super premium, correspondendo a $83,7 \%$ (282) dos tutores de cães e 86,5\% (141) dos tutores de gatos, não havendo diferença significativa no percentual das duas espécies $(\mathrm{p}=0,412)$.

De todos os tutores entrevistados, $60,8 \%$ (304) reconheceram que a ração vendida em embalagem fechada é mais segura e possui melhor qualidade nutricional quando comparada 
à ração vendida a granel. Correspondendo a $61,1 \%$ (206) de todos os tutores de cães e $60,1 \%$ (98) dos tutores de gatos, também não havendo diferença significativa entre as respostas $(\mathrm{p}=$ 0,829).

Dos 500 tutores entrevistados, 310 (62\%) alegaram se basear em alguma característica como o cheiro $(31,4 \%)$, o formato do grão $(18,2 \%)$ ou a cor $(13 \%)$ no momento da escolha do alimento. Cento e noventa tutores (38\%) afirmaram não selecionar o alimento por nenhuma característica física, e três tutores $(0,6 \%)$ não souberam responder à pergunta, não havendo diferença significativa entre as respostas dos tutores de cães e de gatos $(p=0,564)$.

Esse resultado reforça a afirmação de que grande parte dos tutores das cidades selecionadas ainda participa pouco nas decisões e seleção consciente de alimentos para seus animais. No entanto, como a maioria (60\%) declarou considerar características físicas no momento da compra, podemos sugerir que estes estão em busca de reconhecer a qualidade dos alimentos por meio de supostos indicadores de qualidade embora cor, odor e formato dos grãos não estejam diretamente relacionados à qualidade da ração, podendo levar o tutor a equivocar-se no momento da escolha.

Esse erro está propenso a acontecer quando se tenta fazer referência à alimentação humana, onde quanto mais colorida mais rica em nutrientes a refeição será, por exemplo. No caso das rações comerciais essa afirmativa não é verdadeira, pois apesar de, supostamente, todos os alimentos comerciais vendidos no Brasil serem balanceados, a qualidade dos ingredientes e o acréscimo de aditivos interferem diretamente na qualidade final daquele produto. Algumas marcas, inclusive, usam dessa ideia para desenvolver o marketing do seu produto, quando ilustram as embalagens de forma colorida e com representação de vários vegetais, induzindo o consumidor a relacionar aquela ração (colorida artificialmente) a um alimento mais rico em nutrientes e de origem natural. Por outro lado, há ainda a possibilidade de não correspondência entre os dados nutricionais apresentados no rótulo das embalagens, e sua real composição (Carciofi et al., 2006).

Na pergunta seguinte "Você tem o hábito de verificar a composição nutricional na hora da compra da ração comercial?" podemos observar como a ideia de associar a qualidade do produto à sua aparência física gera equívocos aos tutores, induzindo à obtenção, muitas vezes, de produtos de pior qualidade.

Quando perguntados se têm o hábito de observar as informações nutricionais dos alimentos, $75 \%$ (375) dos entrevistados informaram não o fazer, indicando a ideia de que a aparência do produto é o principal critério de escolha.

Esse resultado corrobora com os resultados observados em estudo realizado na cidade de Santa Maria (SC), em 2018, onde 63\% dos tutores entrevistados reportaram não usar as características nutricionais do alimento como fator de escolha no momento da seleção do alimento (Prior et al., 2018).

Ao separarmos esses dados por espécie, observamos que $67,4 \%$ (260) dos tutores de cães não observam as características nutricionais dos alimentos oferecidos aos seus animais, apesar de 92\% (310) terem concordado que a qualidade da alimentação estava diretamente relacionada à prevenção ou causa de doenças. Quanto aos tutores de gatos, 70,6\% (115) também não observam os valores nutricionais das rações comerciais, mesmo após 90,2\% (147) alegarem conhecer o fato de a qualidade alimentar estar fortemente relacionada à saúde do animal. Não foi observada diferença significativa entre as respostas dos tutores de cães e de gatos $(\mathrm{p}=$ 0,110).

O preço do produto como fator de escolha foi a resposta escolhida por $61,4 \%$ (307) dos entrevistados, dado que pode ser justificado pelo tipo de situação socioeconômica do público entrevistado (em sua maioria recebendo até três salários mínimos). Nessa pergunta foi encontrada diferença significativa entre os tutores de cães e gatos $(\mathrm{p}=0,018)$, onde observou-se que o valor da ração é um fator mais importante para os tutores de cães do que os de gatos, como observado também, por Aptekmann et al. em 2013.

Oitenta e nove vírgula quatro por cento dos entrevistados (447) relataram não conhecer o segmento de rações comerciais terapêuticas, não havendo diferença significativa entre as duas espécies $(\mathrm{p}=0,310)$. No começo do questionário, apenas $7,8 \%$ (39) dos entrevistados tinham 
afirmado serem responsáveis por animais que apresentavam algum tipo de doença crônica, dado que vai de encontro ao pequeno número que afirmou ter conhecimento sobre esse tipo de alimentação 10,6\% (53).

As rações terapêuticas comerciais estão entre as que apresentam um maior valor de mercado, quando comparamos o preço do quilograma, desta forma, é uma classe de produtos que apenas é conhecida por tutores de animais com necessidades nutricionais especiais, como é o caso de animais portadores de doenças crônicas. No estudo de Aptekmann et al. (2013) os tutores que forneciam ração terapêutica aos seus animais afirmaram considerar o produto com um preço comercial muito elevado.
A Tabela 3 contém todos os dados de respostas relacionadas à dieta natural formulada, entre elas: se os tutores conheciam esse tipo de alimentação, se tinham conhecimento sobre o procedimento de preparação de uma alimentação natural e se teriam tempo disponível para a preparação de uma alimentação natural para os seus animais.

Pôde-se constatar que 400 dos 500 tutores entrevistados $(80 \%)$ nunca tinham ouvido falar em alimentação natural formulada para animais destes, 78,6\% (265) correspondiam ao total de tutores de cães e $82,8 \%$ (135) ao total de tutores de gatos, não tendo sido observada diferença significativa entre as duas espécies $(p=0,273)$.

Tabela 3 Percepção dos tutores de cães e gatos do brejo paraibano (Alagoa Grande, Areia, Pilões, Guarabira e Serraria) quanto à alimentação natural formulada para animais, o modo de preparo e a disponibilidade para preparála no dia-a-dia

\begin{tabular}{|c|c|c|c|c|}
\hline Questionamento & & Respostas & p-valor & \\
\hline \multirow{4}{*}{$\begin{array}{l}\text { Você já ouviu falar de } \\
\text { alimentação natural } \\
\text { formulada para animal? }\end{array}$} & \multicolumn{2}{|c|}{$\operatorname{Sim}(\% / \mathrm{N})$} & Não (\% / N) & \\
\hline & \multicolumn{2}{|c|}{20 / 100} & 80 / 400 & 0,107 \\
\hline & \multicolumn{2}{|c|}{ Cães / gatos $(\% / \mathrm{N})$} & Cães / gatos $(\% / \mathrm{N})$ & \\
\hline & $21,4 / 72$ & $17,2 / 28$ & $66,3 / 265 \quad 33,7 / 135$ & \\
\hline \multirow{4}{*}{$\begin{array}{l}\text { Você conhece o } \\
\text { procedimento para } \\
\text { preparação do alimento } \\
\text { natural formulado? }\end{array}$} & \multicolumn{2}{|c|}{$\operatorname{Sim}(\% / N)$} & Não (\% / N) & \\
\hline & \multicolumn{2}{|c|}{$7,4 / 37$} & $92,6 / 463$ & 0,281 \\
\hline & \multicolumn{2}{|c|}{ Cães/gatos (\% / N) } & Cães/gatos $(\% / N)$ & \\
\hline & $81,1 / 30$ & $18,9 / 7$ & $66,3 / 307 \quad 33,4 / 156$ & \\
\hline \multirow{4}{*}{$\begin{array}{l}\text { Você teria tempo } \\
\text { disponível para preparar } \\
\text { alimentação natural } \\
\text { formulada para seu(s) } \\
\text { animal(is)? }\end{array}$} & \multicolumn{2}{|c|}{$\operatorname{Sim}(\% / N)$} & Não $(\% / N)$ & \\
\hline & \multicolumn{2}{|c|}{47,2 / 236} & $52,8 / 264$ & $<0,001$ \\
\hline & \multicolumn{2}{|c|}{ Cães/gatos (\% / N $)$} & Cães/gatos $(\% / \mathrm{N})$ & \\
\hline & $64,8 / 153$ & $35,2 / 83$ & $69,7 / 184$ & \\
\hline
\end{tabular}

$\mathrm{N}$ - frequência absoluta. \% - frequência relativa percentual. Intervalos com 95\% de confiança. Teste Qui-quadrado de Pearson.

Apesar de ser considerada em algumas situações como uma forma interessante e alternativa de alimentação disponível para os animais, principalmente quando se considera a prevalência de animais com algum tipo de alergia associada à alimentação com ração comercial, a alimentação natural formulada ainda é desconhecida pela maioria dos entrevistados. Este tipo de alimentação, composta por alimentos crus ou cozidos, apresenta melhor aceitação por parte dos animais, por ser mais palatável, e apresenta melhor digestibilidade do que a ração comercial de segmentos intermediários, como demonstrado no estudo de Algya et al. (2018).

Quando perguntados se tinham conhecimento da forma de preparo da alimentação formulada natural, 92,6\% (463) dos tutores afirmou desconhecer, e após esclarecimento sobre o que era esse tipo de alimentação e como deveria ser preparada, $52,8 \%$ (264) afirmaram não ter 
disponibilidade de preparo e 47,2\% (236) afirmaram ter tempo disponível para a sua realização, sendo 45,4,8\% (153) do total de tutores de cães e $50,9 \%$ (83) do total de tutores de gatos, não tendo sido observada diferença significativa entre as duas espécies $(\mathrm{p}=0,246)$.

A alimentação natural formulada depende da correta preparação e utilização por parte dos tutores, podendo contribuir negativamente para a saúde do animal quando mal preparada ou acondicionada. Mesmo em dietas prescritas por profissionais habilitados, os tutores podem sentirse à vontade para interferir na prescrição original, acrescentando ou retirando alimentos sem a orientação profissional (Halfen et al., 2017; Stockman et al., 2013).

Alguns dos problemas da manipulação indiscriminada deste tipo de alimento que podem ser citados são: o mau uso dos ingredientes, como o uso de carnes ou produtos de origem animal em excesso ou não cozidos, podendo expor o animal a problemas nutricionais, hematológicos, hepáticos, entre outros, também aumenta o risco de contaminação, principalmente por bactérias (Dodd et al., 2019; Hamper et al, 2016; Lyu et al., 2018; Stockman et al., 2013).

Existem ainda os casos de formulação de dietas compostas exclusivamente por vegetais (por ideologia do tutor - dietas vegetarianas ou veganas), que são um verdadeiro desafio quando o assunto é o balanceamento nutricional, pois cães e gatos necessitam de nutrientes provenientes de fontes animais, podendo levar o animal a quadros graves de desnutrição e até à morte, principalmente os gatos, que têm uma necessidade maior de nutrientes de origem animal (Michel, 2006).

A Tabela 4 contém os dados das respostas à pergunta relacionada à alimentação como fator determinante da saúde do animal. Noventa e um vírgula quatro por cento (457) dos entrevistados respondeu afirmativamente à questão, correspondendo a $92 \%$ (310) do total de tutores de cães, e 90,2\% (147) do total de tutores de gatos, não havendo diferença significativa entre os dois tipos de tutores $(\mathrm{p}=0,500)$.

Tabela 4 Reposta dos tutores de cães e gatos do brejo paraibano quanto à relação da alimentação como possível forma de causar ou evitar doenças

\begin{tabular}{lccr}
\hline \multicolumn{1}{c}{ Questionamento } & \multicolumn{3}{c}{ Respostas } \\
\hline Você acha que alimentação é & Cães $(\% / \mathrm{N})$ & Gatos $(\% / \mathrm{N})$ \\
um fator determinante para a & $91,4 / 457$ & $8,6 / 43$ & \\
saúde do(s) animal(is) e que & Cães / gatos $(\% / \mathrm{N})$ & Cães $/$ gatos $(\% / \mathrm{N})$ & p-valor \\
ela pode evitar ou provocar & $67,8 / 310 \quad 32,2 / 147$ & $62,8 / 27 \quad 37,2 / 16$ & 0,500 \\
doenças? & & & \\
\hline
\end{tabular}

$\mathrm{N}$ - frequência absoluta. \% - frequência relativa percentual. Intervalos com 95\% de confiança. Teste Qui-quadrado de Pearson.

Esse achado corrobora o encontrado por Aptekmann et al. (2013), que em seu estudo com tutores de cães e gatos domiciliados no estado de Espírito Santo, encontrou uma prevalência superior a $90 \%$ de respostas positivas a uma pergunta semelhante. A mesma também se correlacionou a alimentação à prevenção ou causa de doenças nos animais, não havendo diferença significativa entre os tutores de cães e de gatos.

Após responderem à questão anterior, os tutores que escolheram o "sim" deveriam responder a outra questão, selecionando qual dos fatores listados no questionário era considerado como o principal fator de risco para a saúde dos seus animais.

Dos 457 tutores que responderam à segunda parte da pergunta, 29,6\% (148) responderam que o uso de sobras de mesa, provenientes da alimentação humana era o maior fator de risco para doenças nos animais. Vinte e três vírgula quatro por cento (117) escolheram o uso de ração comercial de baixa qualidade como principal fator de risco, 17,4\% (87) afirmaram que oferecer alimento em quantidade inadequada era o maior fator de risco, seguidos de $11,4 \%$ (57) que responderam que qualquer ração comercial oferece riscos à saúde dos animais, havendo diferença significativa para essa questão entre cães $(14,2 \%)$ e gatos $(5,5 \%)$, onde $\mathrm{p}=0,009$. Por fim $9,6 \%$ (48) dos tutores associaram o uso de alimentação natural desbalanceada como principal fator de risco para os animais, não havendo diferença significativa entre as espécies.

Quando perguntados se achavam possível curar ou tratar doenças através da manipulação 
dos nutrientes, 60,6\% (303) afirmaram não ser possível, e 39,4\% (197) afirmaram que era possível. Quando analisados por espécie, observou-se uma diferença significativa entre as respostas de tutores de cães e de gatos $(\mathrm{p}=0,028)$ onde $57,3 \%$ (193) dos tutores de cães e $67,5 \%$ (110) dos tutores de gatos escolheram a alternativa negativa.

Porém, quando indagados de qual forma alimentação poderia tratar ou curar uma doença, $83 \%$ (164) não souberam informar de que forma isso seria possível, $10 \%$ (21) sugeriram ser possível pela manipulação do alimento de acordo com a necessidade, 5\% (10) responderam que seria uma ajuda ao animal e 2\% (4) afirmaram já ter tido experiência com esse tipo de manipulação alimentar. Não houve diferença significativa entre as respostas dos tutores de cães e de gatos.

$O$ fato de a informação estar mais acessível aos tutores faz com que aumente a consciência sobre aspectos importantes do manejo animal, especialmente quanto à alimentação (Aptekmann et al., 2013). Essa facilidade de informar-se proporciona um perfil mais crítico dos tutores em relação ao cuidado com os animais, estimulando todo o mercado PET a ajustar-se às suas exigências, em nível de alimentação, trazendo para $\mathrm{o}$ foco $\mathrm{o}$ trabalho de profissionais importantes, como os nutricionistas animais (Borges; Salgarello; Gurian, 2015).

Cinquenta e cinco vírgula nove por cento dos entrevistados (279) já tinham ouvido falar do trabalho do nutricionista animal e 44,2 (221) nunca tinham ouvido que existia esse tipo de profissional, não havendo diferença significativa entre os tutores de cães e gatos ( $\mathrm{p}=0,176)$.

Quando questionados se os seus animais eram ou já tinham sido acompanhados ou avaliados por um nutricionista animal, 81,8\% (409) dos entrevistados responderam que não e 18,2\% (91) afirmaram que sim, não havendo diferença significativa entre as respostas dadas pelos tutores de cães e de gatos $(p=0,869)$.

Sobre o porquê de levar um animal para acompanhamento com esse tipo de profissional, $33,4 \%$ (167) afirmaram não saber, 19,6\% (98) escolheram doenças gerais como resposta, $14,6 \%$ (73) responderam obesidade, 13,2\% (66) iriam para receber orientação sobre a forma correta de alimentar , 6,2\% (31) escolheram os motivos de magreza ou pelagem feia dos animais, 4,8\% (24) se os animais apresentassem perda de apetite, $3,4 \%$ (17) iriam para conhecer melhor esse tipo de atendimento, $2,8 \%$ (14) levariam os animais se estivessem debilitados e, por fim, $2 \%$ (10) levariam para fazer uma avaliação nutricional. Mais uma vez não houve diferença significativa entre as respostas dos tutores das duas espécies.

Por fim, perguntou-se se os tutores levavam os animais ao atendimento veterinário com frequência ou se levavam apenas quando o animal adoecia. Oitenta vírgula quatro por cento (402) alegaram levar os seus animais apenas quando adoeciam e 19,6\% (98) afirmaram levar seus animais frequentemente para serem examinados. Quando avaliamos por espécie, 79,2\% dos tutores de cães e $82,8 \%$ dos tutores de gatos levavam seus animais ao veterinário apenas quando adoeciam, não havendo diferença significativa $(\mathrm{p}=0,343)$.

O trabalho de Gomes (2015), realizado na cidade de Areia, durante o período da campanha de vacinação contra a raiva, também observou uma maior frequência por parte dos tutores que levaram os animais ao veterinário apenas quando estavam doentes $(52,6 \%)$.

\section{Conclusões}

Os tutores de cães e gatos da região do Brejo paraibano mostraram-se atentos ao papel da nutrição na saúde, prevenção e auxílio no tratamento de doenças. No entanto, não aplicam este conhecimento corretamente, pois demonstraram pouca participação e ausência de critérios nutricionais para guiar a escolha do alimento mais adequado;

$\mathrm{O}$ valor comercial ainda é fator preponderante na escolha do alimento, reflexo da condição socioeconômica da amostra estudada. No entanto, dentre os motivos levantados, a falta de orientação também mostrou-se ser um fator importante. Esta lacuna identificada, entre o conhecimento pré-existente e a conduta do tutor, precisa ser repensada e corrigida pelos profissionais que atuam na área, seja na criação de oportunidades para comunicação com o cliente na clínica ou nos pontos de venda de produtos;

Com relação aos principais manejos alimentares os tutores de gatos aparentam maior cuidado com a alimentação de seus animais. Alimentos alternativos às rações industrializadas de uso diário ainda são impopulares na região. 


\section{Referências}

Algya, K. M.; Cross, T. L.; Leuck, K. N.; Kastner, M. E.; Baba, T.; Lye, L.; Godoy, M. R. C. de; Swanson, K. S. Apparent total tract macronutrient digestibility, serum chemistry, urinalysis, and fecal characteristics, metabolites and microbiota of adult dogs fed extruded, mildly cooked, and raw diets. Journal of Animal Science, v. 96, n. 9, p. 3670-3683, 2018. https://doi.org/10.1093/jas/sky235

Aptekmann, K. P.; Mendes-Junior, A. F.; Suhett, W. G.; Guberman, U. C. Manejo nutricional de cães e gatos domiciliados no estado do Espírito Santo - Brasil. Arquivo Brasileiro de Medicina Veterinária e Zootecnia, v. 65, n. 2, p. 455-459, 2013. http://dx.doi.org/10.1590/S010209352013000200022

Beça, M. F. F. Estudos sobre preferência de alimentos compostos completos para cães. 2013. 3f f. Dissertação (Mestrado em Medicina Veterinária) - Instituto de Ciências Biomédicas Abel Salazar, Universidade do Porto, Porto, 2013.

Borges, F. M. O. Aspectos nutricionais de cães e gatos em várias fases fisiológicas - animais em crescimento $\mathrm{x}$ mantença $\mathrm{x}$ gestante $\mathrm{x}$ idoso. I Curso de Nutrição de Cães e Gatos FMVZUSP. São Paulo, 2009. 34p.

Borges, F. M. O.; Salgarello, R.M.; Gurian, T. M. Recentes avanços na nutrição de cães e gatos. ReseachGate, $32 \quad$ p., 2015. https://wp.ufpel.edu.br/nutricaoanimal/files/2011/03/Ava n\%C3\%A7os_caes_gatos.pdf

Brambillasca, S.; Purtscher, F.; Britos, A.; Repetto, J. L.; Cajarville, C. Digestibility, Fecal characteristics, and plasma glucose and urea in dogs fed a commercial dog food once or three times daily. The anadian Veterinary Journal. Canadá, v. 51, n. 2, p. 190-194, 2010. https://pubmed.ncbi.nlm.nih.gov/20440906

Carciofi, A. C.; Vasconcellos, R. S.; Borges, N. C.; Moro, J. V.; Prada, F.; Fraga, V. O. Composição nutricional e avaliação de rótulo de rações secas para cães comercializadas em Jaboticabal-SP. Arquivo Brasileiro de Medicina Veterinária e Zootecnia, v. 58, n. 3, p. 421-426, 2006. http://dx.doi.org/10.1590/S010209352006000300021

Deng, P.; Iwasaki, E.; Suchy, S. A.; Pallotto, M. R.; Swanson, K. S. Effects of feeding frequency and dietary water content on voluntary physical activity in healthy adult cats. Journal of Animal Science, v. 92, n. 3, p. 1271-1277, 2014. https://doi.org/10.2527/jas.2013-7235

Dodd, S. A. S.; Cave, N. J.; Adolphe, J. L.; Shoveller, A. K.; Verbrugghe, A. Plant-based (Vegan) diets for pets: A survey of pet owner attitudes and feeding practices. PLOS One, v. 14, n. $\quad 1, \quad 19 \quad$ p., 2019. https://doi.org/10.1371/journal.pone.0210806

Garcia, R. C. M. Estudo da dinâmica populacional canina e felina e avaliação de ações para o equilíbrio dessas populações em área da cidade de São Paulo, SP, Brasil. 265 f. Tese (Doutorado em Epidemiologia Experimental e Aplicada em Zoonoses) Faculdade de Medicina Veterinária e Zootecnia, Universidade de São Paulo, São Paulo, 2009.

Gomes, V. C. P. S. Relação entre padrão socioeconômico e variáveis ligadas ao bem estar e guarda responsável de cães e gatos em Areia-PB. 42 f. Monografia (Graduação em Medicina Veterinária) - Universidade Federal da Paraíba, Areia, 2015.

Halfen, D. P.; Oba, P. M.; Duarte, C. N.; Santos, J. P. F.; Vendramini, T. H. A.; Sucupira, M. C. A.; Carciofi, A. C.; Brunetto, M. Tutores de cães consideram a dieta caseira como adequada, mas alteram as fórmulas prescritas. Pesquisa Veterinária Brasileira, v. 37, n. 12, p. 14531459, 2017. https://doi.org/10.1590/s0100736x2017001200015

Hamper, B. A.; Bartges, J. W.; Kirk, C. A. Evaluation of two raw diets vs a commercial cooked diet on feline growth. Journal of Feline Medicine and Surgery, v. 19, n. 4, p. 424-434, 2017. https://doi.org/10.1177/1098612X16634388

Instituto Brasileiro de Geografia e Estatística IBGE. Painel de indicadores, 2013. Disponível em: < https://www.ibge.gov.br/indicadores >. Acesso em 24 de Jan. de 2018.

Lyu, T.; Liu, G.; Zhang, H.; Wang, L.; Zhou, S.; Dou, H.; Pang, B.; Sha, W.; Zhang, H. Changes in feeding habits promoted the differentiation of the composition and function of gut microbiotas between domestic dogs (Canis lupus Familiaris) and gray wolves (Canis lupus). AMB Expres, v. $8, \quad$ n. 123,12 p., 2018. http://dx.doi.org/10.1186/s13568-018-0652-x 
Michel, K. E. Unconventional diets for dogs and cats. Veterinary Clinics Small Animal Practice, v. 36, n. 6, p. 1269-1281, 2006. https://doi.org/10.1016/j.cvsm.2006.08.003

Ogoshi, R. C. S., Reis, J. S., Zangeronimo, M. G., Saad, F. M. O. B. Conceitos básicos sobre nutrição e alimentação de cães e gatos. Ciência Animal, v. 25, n. 1, p. 64-75, 2015. http://www.uece.br/cienciaanimal/dmdocuments/palestra 06_p64_75.pdf

Pedrinelli, V.; Gomes, M. O.S.; Carciofi, A.C. Analysis of recipes of home-prepared diets for dogs and cats published in portuguese. Journal of Nutritional Science, v. 6, e-33, 2017. http://dx.doi.org/10.1017/jns.2017.31

Prior, V. D. R.; Ferreira, P. B.; Prade, M. N.; Moro, A. S.; Costa, G. P.; Rosatto, D. M.; Deolindo, R. G.; Silveira, W. B. Percepções e comportamento de tutores de cães e gatos frente ao mercado Pet Food. $\mathbf{2 8}^{\mathbf{o}}$ Congresso Brasileiro de Zootecnia. 2018.

Remillard, R. L. Homemade diets: attributes, pitfalls, and a call for action. Topics in
Companion Animal Medicine, v. 23, n. 3, p. 137-142, 2008. https://doi.org/10.1053/j.tcam.2008.04.006

Saad, F. M. O. B.; França, J. Alimentação natural para cães e gatos. Revista Brasileira de Zootecnia, v. 39, p. 52-59, 2010. https://doi.org/10.1590/S1516-35982010001300007

Stockman, J.; Fascetti, A. J.; Kass P. H.; Larsen, J. A. Evaluation of recipes of home-prepared maintenance diets for dogs. Journal of the American Veterinary Medical Association, v. 242, n. 11, p. 1500-1505, 2013. https://doi.org/10.2460/javma.242.11.1500

WSAVA. Diretrizes para a avaliação nutricional - WSAVA. Disponível em: < http://www.wsava2016.net/mobile/index.html $\# \mathrm{p}=34 \quad>$. Acesso em: 12 de Fev. de 2019.

Zicker, S. C. Evaluating pet foods: how confident are you when you recommend a commercial pet food? Topics in Companion Animal Medicine, v. 23, n. 3, p. 121-126, 2008. https://doi.org/10.1053/j.tcam.2008.04.003 